\title{
Carcinoma de células escamosas em prepúcio de equino
}

Luane Camargo Zeni", Pedro Lara, Eros Luis de Sousa, Pedro Vicente Michelotto Jr., Luciana Doria Ribeiro Cabral

Pontifícia Universidade Católica do Paraná (PUCPR), Curitiba, PR, Brasil

*Autor correspondente

e-mail: luanezeni@yahoo.com.br

\section{Resumo}

Dentre as neoplasias epiteliais, o carcinoma de células escamosas (CCE) é a mais comum em equinos machos, pois se registra como a principal neoplasia do pênis e prepúcio em animais castrados, de qualquer idade, não necessariamente de origem metastática. A região despigmentada e desprovida de pêlos é fator que auxilia no aparecimento do CCE e os sintomas se agravam com o efeito da radiação solar. 0 primeiro sinal clínico é a dermatose solar, a qual ao evoluir, na neoplasia se observa eritema, edema e descamação seguidos de formação de crostas e adelgaçamento da epiderme e subsequente ulceração. Com o tempo, o tumor invade a derme e as áreas tumorais se tornam mais firmes, as úlceras aumentam de tamanho e profundidade. 0 diagnóstico é realizado através do exame histopatológico e o tratamento adequado é a excisão cirúrgica da neoplasia quando localizado no prepúcio. 0 presente caso, objetivou analisar e comparar a eficácia de diferentes tratamentos para o carcinoma de células escamosas na região do prepúcio de equinos. Um equino, macho, 18 anos, sem raça definida, tordilho, foi atendido na Unidade Hospitalar de Animais de Fazenda - PUCPR. Ao exame físico, o animal não apresentou alterações nos parâmetros fisiológicos. Durante a inspeção do prepúcio, pôde-se perceber grande massa na parede interna de aproximadamente $12 \mathrm{~cm}$ de largura e $7 \mathrm{~cm}$ de profundidade, com consistência firme e aspecto ulcerativo com presença de secreção sanguinolenta e purulenta, além do odor fétido. Foi estabelecido ao animal o tratamento com antibiótico por 10 dias e anti-inflamatório durante seis dias. No 6º dia de tratamento, o animal foi submetido à criocirurgia peritumoral, com nitrogênio líquido, sob anestesia geral intravenosa. Foi retirado um fragmento para biópsia histopatológica, a qual posteriormente confirmou a suspeita de CCE. Desde então, o animal iniciou tratamento com Firocoxib por 10 dias e curativo diário com clorexidina 2\% e água, pomada tópica nitrofural e spray repelente. Após oito dias da realização da criocirurgia, foi feito o debridamento da ferida ulcerada, com auxílio de bisturi, pois seu aspecto era de tecido necrótico, reavivando assim toda a lesão. Em seguida, 
foi aplicado nitrogênio líquido e seguiu-se com o mesmo tratamento proposto. Observou-se no 15ㅇa dia que houve mínima regressão no tamanho da massa tumoral e pouca melhora no aspecto macrológico, porém, como se trata de tumor, indicou-se exérese total da massa. Após quatro meses, o cavalo retornou ao hospital e observou-se proliferação da massa tumoral no prepúcio, apresentando $20 \mathrm{~cm}$ de comprimento e $15 \mathrm{~cm}$ de profundidade, atingindo até a musculatura retoabdominal. Sendo assim, foi proposto um tratamento de quimioredução, com cisplatina, da massa para posteriormente realizar a excisão cirúrgica do tumor. Alguns autores descrevem o CCE como a neoplasia que ocorre com mais frequência no pênis e prepúcio, assim como nas junções muco cutâneas, sendo na sua maioria malignos como no caso exposto. Compreende-se também que o CCE é um tumor invasivo e de alto índice de recorrência. Os CCE são evidenciados como pequenos tumores onde o estágio inicial do desenvolvimento dessa neoplasia em animais castrados é um processo inflamatório em forma de placas, que fica evidenciada na região da reflexão prepucial, área essa delimitada pela dobra da pele que invagina e não é visualizada externamente; porém, nos quadros mais avançados, podem afetar áreas maiores do revestimento prepucial com lesões adjacentes ao pênis. Existem várias modalidades de tratamento para o CCE, incluindo cirurgia nos quadros onde o tumor possui tamanho superior a $1 \mathrm{~cm}$, criocirurgia indicada para neoplasmas superficiais e não invasivos, radiação ionizante, quimioterapia e terapia fotodinâmica. Por se tratar de um tumor maligno e altamente invasivo, deve-se atentar ao uso de técnicas adjuvantes juntamente com a excisão cirúrgica, correlacionando assim uma menor taxa de recidiva.

Palavras-chave: Neoplasia. Cavalo. Prepúcio. 